\title{
THE PROTECTION OF HUMAN RESOURCES' PERSONAL DATA WITHIN MODERN ORGANIZATIONS
}

\author{
Cătălina SITNIKOV \\ Faculty of Economics and Business Administration, University of Craiova \\ inasitnikov@yahoo.com \\ Anca BĂNDOI \\ Faculty of Economics and Business Administration, University of Craiova \\ anca.bandoi01@yahoo.com \\ Camelia-Maria OLARI PERJU \\ Faculty of Economics and Business Administration, University of Craiova \\ camelia.olari@gmail.com \\ Ionut RIZA \\ Faculty of Economics and Business Administration, University of Craiova \\ rizaionut@gmail.com
}

\begin{abstract}
This article aims to analyze a subject that affects human resources daily, regardless of the organization they are part of, and namely the protection of personal data. In order to accomplish the attributions of the job or to observe certain legal requirements, the receipt, storage, accessing, transmission, transport, use and keeping of documents containing personal data should be made exclusively by employees trained with regard to the protection of the personal data. The scientific novelty of this article is indisputable, the problem of the human resources' personal data confidentiality being a real one. Few employees would feel comfortable if their name, address, profession would be published on a web site without their consent. And fewer would be pleased if the disclosure would also contain information on their medical record or that of their children. Even if private life and not only private life, but also the personal rights in general, are nowadays exploited by the processing of unimaginable amounts of information in the digital universe, the law does offer some effective tools for not accepting the loss of private life, the only condition being to know how to invoke them. The purpose of this article is to examine the main procedures for the protection of human resources' personal data within organizations.
\end{abstract}

Keywords: personal data, human resources, organizations, procedures, employees.

JEL classification: M15

DOI: $10.12948 / \mathrm{ie} 2019.05 .04$

\section{Introduction}

Data safety is represented by all the important protection measures taken in the case of accidental or intrusive destruction, unauthorized modification or disclosure of this information [1]. The development and continuous growth of the complexity of the means and methods of automating the processes of human resources' data processing within an organization, increase their vulnerability. The main factors favoring these vulnerabilities are: rapid amplification of the accumulated, stored and processed data volume by computers and other automated means in all domains; the concentration into unique data bases of the sole information related to human resources, with different destinations and nexus; the sudden widening of the users' circle with direct access to the resources and dates of computing systems; the automation of the 
information exchange between more computing systems found at great distances and interconnected into networks [2].

In such circumstances, it is vulnerable twice: on the one hand it is possible to distort or destroy the data, that is to say, to damage its physical integrity, and on the other hand there is the possibility of unauthorized use of the data, that is to say the leakage of the data from the restricted use circle. Studies and surveys on the problem of employees' personal data protection have begun in various countries 20-25 years ago. Although in the last 10-15 years research has been completed with promising results, time has shown that aspects regarding the protection of human resources' data are far from being solved. Many recommendations are too complicated to be realistic, and problems with computer protection are likely to cause new connections between various activity fields. Nowadays, we can identify three action directions in the protection of human resources' data: the theoretical research, the realization of some means of protection and the substantiation of the processes for using the means of protection in automated systems.

In this study, we aim at defining the main procedures that need to be implemented by the organizations, regardless of the domain in which it operates, when it comes to the protection of human resources' personal data.

\section{Literature review}

In an informed society, the collection, stocking, processing and use of personal information is an integrated part of the inter-human relationships and are applied to the economic, micro and macro-political relationships [3]. The disciplinary, control, normalizing, and supervision apparatus would be nothing to do without the information collection, and the same thing applies to the numerous social relations that are affected by the power relations: work, education, commerce, consumption, administration relations [4]. The reliable and safe collection of personal data with regard to the employees of an organization greatly contributes to its efficiency and productivity [4]. However, the organization sometimes evolves and improves many times not in the benefit, but in the detriment of the human resources, and one of the costs of this improvement is the loss of employee privacy" [5]. This can be defined as ,the result of interconnecting the basic, daily life elements with various concepts related to private life, such as determining one's personality without external interference; taking autonomous related to the spiritual, physical, intimate, social and family environment without interference; finding your own way in life without external pressure and so on” [4]. In other words, ,privacy grants you the freedom of being yourself" [6]. The development of information technology has brought legislators into a difficult situation after the appearance of the computer and the first computerized databases. And this was just the beginning of a complex and dull process, which has not yet been completed, because, ,the cyber space imposes a new meaning of the way in which the law works" [7]. In this regard, Hondius wrote in 1975 that, the first difficulty (of the legislators) is their own unfamiliarity, and that of the public, with the computerization and the electronic processing of the data. In front of a powerful computer, human resources have no guarantee that this means will not use unknown capacities against them" [6].

In the United States of America, in the 60's, the problem of collecting information into data bases had become one of the most problematic social determinants of the American society. In the American Congress, in 1965, they expressed fears related to the computerized man, to a file society and they held multiple audiences in both Congress Chambers at the end of 60's and beginning of the 70's. The European Union harmonized in 1995 the national legal framework on the protection of personal data in the Member States through the adoption of Directive 95/46 / EC on the protection of personal information as regards the processing of personal data and the free circulation of such data. Directive 95/46 / EC had a significant impact in the field of 
personal data protection not only in the European Union, but also worldwide.

The fast development of the IT and the specialization of personal data processing have made it necessary, at least in the European Union, to obtain a regulation of sectoral regulations for electronic communications, thus adopting Directive 2002/58/CE regarding the processing of personal data in the area of public communication.

\section{Research and used method}

The purpose of the research is the assessment of the main processes to be applied in the organizations dealing with the protection of human resources' personal data. In the research we involved 150 managers from Romania, from four organizations in the medical, IT, production and industry areas. The research was undergone in the period December $2018 \div$ February 2019 . The research was based on the use of the questionnaire that was sent by mail and the sampling size in this study has been simple random sampling.

In the socio-economic universe, the economic decision assisting problems are generated by the multi-criteria decision processes; this is why we used the maximum global utility method in the study. The model tries to use, at maximum, in a scientific way, the informational base, and the procedures for imitating the rational mode of decision-making is, in more or less elaborate forms, the conceptual essence of the models.

The steps of the global utility method are as follows:

Step 1. We build the utilities matrix with the elements, $X_{i j}, i=1, \ldots, r$ and $j=1, \ldots, n$.

Each matrix element is calculated for the maximum criterion with the expression:

$$
x_{i j}=u_{i j}=\frac{x_{i j}-x_{i \min }}{x_{i \max }-x_{i \min }}
$$

and each minimum criterion with the expression:

$$
x_{i j}=u_{i j}=\frac{x_{i \max }-x_{i j}}{x_{i \max }-x_{i \min }},
$$

where:

$$
\begin{aligned}
& x_{i j}=\text { value of the } \mathrm{i} \text { indicator associated to the } \mathrm{j} \text { indicator; } \\
& x_{i \max }=\text { minimum value of the } \mathrm{i} \text { indicator; } \\
& x_{i \min }=\text { maximum value of the } \mathrm{i} \text { indicator. }
\end{aligned}
$$

Step 2. We calculate the global utility for each project, as the sum of the products between the utility matrix elements (the column vector corresponding to the project) and the importance coefficient given for each indicator.

$$
U G_{j}=\sum_{i=1}^{r} \alpha_{i} u_{i j} \text { unde } \sum_{i=1}^{r} \alpha_{i}=1
$$

Step 3. We choose the project to which the $V_{j}$ maximum global utility corresponds.

$$
\max \left\{U G_{j}\right\} \Rightarrow V_{j} \quad \mathrm{j}=1, \ldots, \mathrm{n}
$$

For differentiating a decisional Vi variant (given $\mathrm{n}$ variants), and for selecting the best offer by simultaneously considering various assessment criteria $\left(C_{j}, j=1, \ldots, n\right)$ we use the maximum global utility method. Finding the best combinations of attributes (characteristic of a variant) forms the object of the multi-attribute problem. This involves the transformation of all number values $\mathrm{a}_{\mathrm{ij}}$ (expressed in the associated measure units) and qualitative characteristics in utilities $\mathrm{u}_{\mathrm{ij}}$, i.e. numerical values (dimensionless) located in the range [0,1]. The basic hypothesis in the correct functioning of the weighted sum method is the criteria independence. The greatest of the synthesis utilities shows the best variant. 
The research is based on the analysis of the application method of the main protection procedures for the human resources' personal data. In the process of analyzing the dates, the protection of the human resources' personal data was approached as a system consisting of five categories of procedures:

P1-Procedures for editing, registering, collecting (handling) and transporting documents containing personal data;

P2-Specific procedures for accessing, processing and protecting personal data;

P3-Procedures for the protection and security of computer systems where the personal data is stored and processed;

P4-Procedures for the conservation of personal data - collected and processed;

P5-Procedures for the protection of personal data within the HR and Accounting departments. In Table 1 we can see the information base of the study, namely the importance given by the managers to each procedure for protecting the human resources' personal data.

Table 1. The importance of applying the procedures

\begin{tabular}{|c|c|c|c|c|}
\hline \multirow{2}{*}{$\begin{array}{c}\text { APPLIED } \\
\text { PROCEDURE }\end{array}$} & $\begin{array}{c}\mid 4 \\
\text { ORGANIZATION ACTIVITY AREA } \\
\end{array}$ & $\begin{array}{c}\text { IT \% } \\
(v 2)\end{array}$ & $\begin{array}{c}\text { PRODUCTION \% } \\
(v 3)\end{array}$ & $\begin{array}{c}\text { MEDICAL \% } \\
(v 4)\end{array}$ \\
\hline P1 $(c 1)$ & 16.45 & 22.35 & 27.5 & 12.5 \\
\hline P2 $(c 2)$ & 10.55 & 15.15 & 11.9 & 23.61 \\
\hline P3 $(c 3)$ & 8.9 & 13.25 & 9.8 & 10.54 \\
\hline P4 $(c 4)$ & 23.45 & 16 & 11.82 & 23.55 \\
\hline P5 $(c 5)$ & 40.65 & 33.25 & 38.98 & 29.8 \\
\hline
\end{tabular}

Source: created according to the model found in Ratiu-Suciu Camelia "Modelarea \& Simularea proceselor economice. Teorie si practica” [5]

The main results indicate that managers first take into consideration $P 5$ - the procedure for the protection of personal data within the HR and Accounting departments, and last P3 procedure for the protection and security of computer systems where the personal data is stored and processed (figure 1).

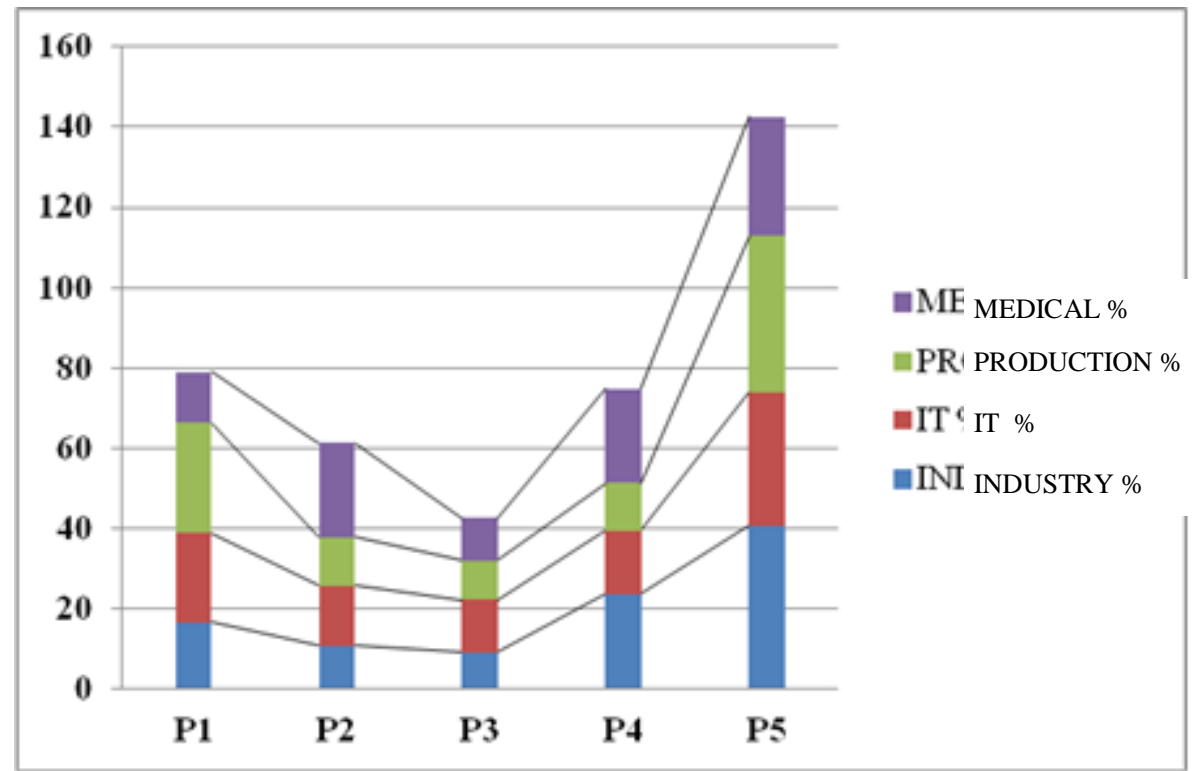

Figure 1. The importance of applying the protection procedures for personal data Source: the author's own concept 
www.conferenceie.ase.ro

The execution of the calculation algorithm implied:

Step 1 - building the unit matrix with the elements $\mathrm{x}_{\mathrm{ij}}$ figure 2.

$\left[\begin{array}{llll}0.26 & 0.66 & 1.00 & 0.00 \\ 1.00 & 0.65 & 0.90 & 0.00 \\ 0.00 & 1.00 & 0.21 & 0.38 \\ 0.99 & 0.36 & 0.00 & 1.00 \\ 0.00 & 0.68 & 0.15 & 1.00\end{array}\right]$

Figure 2. Unit matrix

Source: the author's own concept

Step 2 - Calculating the global utilities for each organization (table 2):

Table 2. Results of the global utilities calculation

\begin{tabular}{|c|c|}
\hline GLOBAL UTILITY & RESULT \\
\hline INDUSTRY & 2.25 \\
\hline IT & 3.34 \\
\hline PRODUCTION & 2.26 \\
\hline MEDICAL & 2.38 \\
\hline
\end{tabular}

Source: the author's own concept

Step 3 - Table 2 shows us that by the global utilities' calculation, the highest global utility belongs to the IT organization.

Thus, by applying the algorithm to calculate the maximum global utility, it can be concluded that the IT organization has best assessed the importance of the procedures regarding the protection of human resources' personal data.

\section{Conclusions}

By means of minimum-security requirements, a complex of technical, informational, organizational, logistical, and safety measures have been developed to ensure the minimum level of security regarding the protection of human resources' personal data.

For the best protection of human resources' personal data, any organization must implement at least the following basic procedures:

1. Procedures for editing, registering, collecting (handling) and transporting documents containing personal data:

All participants / users within organizations who have access to personal data must sign a confidentiality agreement. To obtain access to personal data, users need to log into the organization's system. Authentication within computer systems should be done through the introduction of unique and non-transmissible authentication credentials obtained as a result of the process of enrolment and management of electronic identity, which is governed by the safety policies in force. Each user has his or her own ID (user name). Never allocate the same identification code to more users and it cannot be shared by more users.

2. Procedures for the protection and safety of information systems:

Any organization that processes human resources' personal data and registers them into the information systems must ensure the protection and security of the computer systems that are storing and processing the personal data, observing the legal regulations in force. 
www.conferenceie.ase.ro

\section{Procedures for the conservation of personal data - collected and processed:}

The organization has the right to register and process personal data only if data has been voluntarily provided by the human resources, by means of acts, documents, forms, subscriptions to newsletter, the creation of an account, or by submitting certain documents online (by e-mail).

4. Procedures for the protection of personal data within the HR and Accounting departments: Within any organization, regardless of the area of activity, we must identify the documents that include personal data, and which must be accordingly protected, namely: CVs, labor contracts, certificates, copies of documents, qualifications, documents regarding trainings etc.

In order to keep a clear evidence of those categories, we must create specific registers for the $\mathrm{HR}$ and the Accounting department, for the types of processed documents and their processing flow.

5. Procedures regarding the use of internet and e-mail:

Each organization employee must be responsible for the correct use of the internet and e-mail, and to do it according to this policy. The email should be used only for the purpose of performing the work tasks. The use of the e-mail system for personal purposes must be forbidden.

The employees can use the company's internet connection for the following purposes:

a) fulfilling work tasks;

b) using information to improve their activity.

Any organization must adopt technical and organizational measures for the protection and safety of information systems in which the human resources' personal data is stored and processed, and also adequate technical and organizational measures for protecting personal data against accidental or illegal damage, loss, change, disclosure or unauthorized access to the information systems in which the personal data is stored.

\section{References}

[1] P. Carey, Data Protection: A Practical Guide to UK and EU Law, Oxford University Press, Oxford, United Kingdom, 2018;

[2] H. Wong, Cyber Security: Law and Guidance. Bloomsbury Publishing PLC, London, United Kingdom, 2018.

[3] I. Alexe, N.D. Ploeșteanu and D.M. Șandru, Protectia datelor cu caracter personal, Universitară Publishing House, Bucharest, 2017;

[4] S. Gutwirth, Privacy and the Infonnation Age, Rownan \& Littlefield Publishers.Inc., Lanham, SUA, 2002;

[5] D.C. Danisor, I. Dogaru and G. Danisor, Teoria generala a dreptului, C.H. Beck Publishing House, Bucharest, 2006

[6] F.W. Hondius, Emerging Data Protection in Europe, North-Holland Publishing Company, Amsterdam, 1975

[7] C. Ratiu-Suciu, Modelarea \& Simularea proceselor economice. Teorie si practica, $2^{\text {nd }}$ Ed. Economică Publishing House, Bucharest, 2002. 